\title{
Straightforward One-Pot Syntheses of Silylamides of Magnesium and Calcium via an In Situ Grignard Metalation Method
}

\author{
Sven Krieck \\ Philipp Schüler \\ Jan M. Peschel \\ Matthias Westerhausen* (D) \\ Friedrich Schiller University Jena, Institute of Inorganic and Analytical \\ Chemistry, Humboldtstraße 8, D-07743 Jena, Germany \\ m.we@uni-jena.de \\ Published as part of the 50 Years SYNTHESIS - Golden Anniversary Issue
}

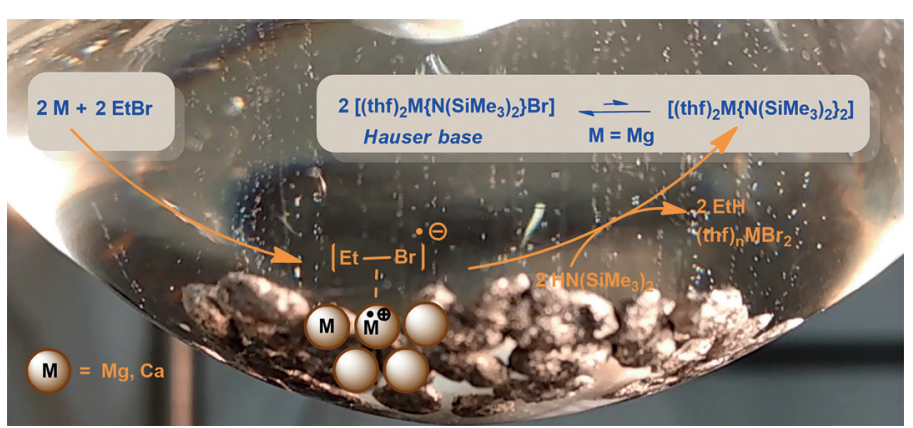

Received: 11.10 .2018

Accepted after revision: 13.11.2018

Published online: 13.12 .2018

DOI: 10.1055/s-0037-1610407; Art ID: ss-2018-z0683-fa

License terms: CC $0 \$$

Abstract Calcium bis[bis(trimethylsilyl)amide] $\left(\mathrm{Ca}(\mathrm{HMDS})_{2}\right)$ is a widely used reagent in diverse stoichiometric and catalytic applications. These processes necessitate a straightforward and large-scale access of this complex. Calcium does not react with primary and secondary amines, but the addition of excess bromoethane to a mixture of calcium turnings and amines in THF at room temperature yields the corresponding calcium bis(amides), calcium bromide and ethane. This in situ Grignard metalation method (iGMM) allows the preparation of calcium bis(amides) from secondary and primary trialkylsilyl-substituted amines and anilines on a multigram scale.

Background

The In Situ Grignard Metalation Method (iGMM)

Properties of $\left[(\text { thf })_{2} \mathrm{M}(\mathrm{HMDS})_{2}\right]$

Applications and Perspective

Key words calcium amides, hexamethyldisilazides, silylamides, alkaline earth metal amides, amidocalcium complexes

\section{Background}

The development of diverse procedures for the synthesis of calcium bis[bis(trimethylsilyl)amides] is based on the desperate need of soluble organocalcium complexes for various applications. Therefore, different strategies were developed independently at the beginning of the 1990s. The first syntheses of calcium bis[bis(trimethylsilyl)amide] $\left(\mathrm{Ca}(\mathrm{HMDS})_{2}\right)$ were performed via transmetalation of $\mathrm{Hg}(\mathrm{HMDS})_{2}{ }^{1}$ or $\mathrm{Sn}(\mathrm{HMDS})_{2},{ }^{2}$ via metathetical approaches of $\operatorname{AHMDS}(\mathrm{A}=$ alkali metal $)$ with calcium alkoxides ${ }^{3}$ or pseudohalides such as trifluoromethanesulfonates (triflates $)^{4}$ and arenesulfonates. ${ }^{5}$ The metathesis reaction of KHMDS with $\mathrm{CaI}_{2}$ in tetrahydrofuran ${ }^{6,7}$ and toluene ${ }^{8}$ yields thf adducts and unsolvated $\mathrm{Ca}(\mathrm{HMDS})_{2}$, respectively. Direct

metalation of (H)HMDS with calcium is very challenging and requires activation of the alkaline earth metal via metal vapor synthesis and co-condensation with the organic solvent. $^{3}$ Alternatively, ammonia-saturated solvents can be used for the direct metalation of (H)HMDS with calcium turnings. ${ }^{9}$ These procedures are depicted in Scheme 1.

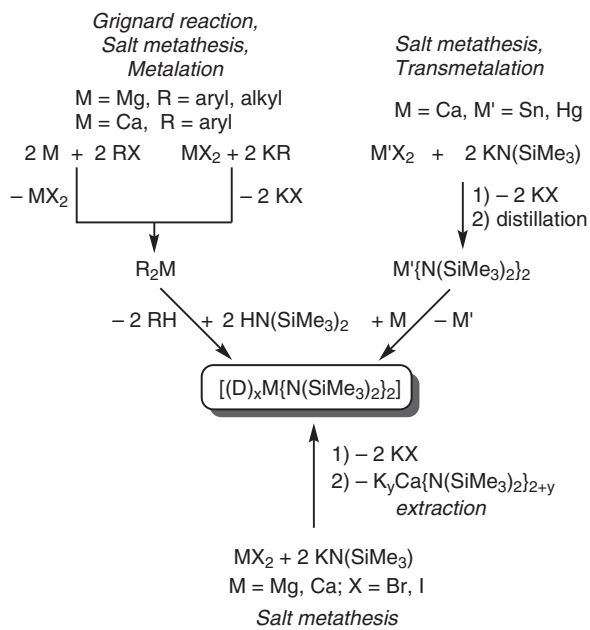

Scheme 1 Common established procedures for the synthesis of $\mathrm{Mg}(\mathrm{HMDS})_{2}$ and $\mathrm{Ca}(\mathrm{HMDS})_{2}$ involving several preparation and purification steps

All these procedures are related to severe drawbacks. Transmetalation protocols require the preparation, isolation and distillation of the precursor organometallics $\left(\mathrm{Hg}(\mathrm{HMDS})_{2}\right.$ or $\left.\mathrm{Sn}(\mathrm{HMDS})_{2}\right)$. Metathetical approaches necessitate an exact stoichiometry to avoid formation of calciates of the type $\left[\mathrm{Ca}(\mathrm{HMDS})_{3}\right]^{-}$(excess of AHMDS) and halide-containing product mixtures (substoichiometric AHMDS). The $\mathrm{Ca}(\mathrm{HMDS})_{2}$ product commonly contains at least traces of potassium (potassium calciate formation 
and/or traces of potassium iodide) that have to be removed by repeated recrystallization efforts. Prior to the direct metalation of (H)HMDS the calcium metal has to be activated to apply pyrophoric metal powders. In our hands, calcium pieces are sluggish in reactions in ammonia-saturated solutions and dull, grayish reaction mixtures are obtained which prohibit the isolation of a pure product. These initial investigations are summarized and evaluated in more detail elsewhere. ${ }^{10}$

Due to these reasons, diverse strategies have been developed to accelerate the synthesis of highly pure $\mathrm{Ca}(\mathrm{HMDS})_{2}$. The reaction of calcium with (H)HMDS in THF can be ensured via addition of $\mathrm{BiPh}_{3}$ under ultrasonication. ${ }^{11}$ The organometallic metalation of (H)HMDS with dibenzylcalcium ${ }^{12}$ circumvents the necessity of metal activation prior to use. Arylcalcium reagents (heavy Grignard reagents $)^{13}$ are easily available and represent suitable metalation reagents for the syntheses of calcium amides. ${ }^{14}$
Drawbacks of these procedures are obvious because another metalorganic precursor is required to prepare the metalation reagent.

The bis(trimethylsilyl)amido ligands guarantee not only solubility of the respective metal complexes in common organic solvents, but variations of this anion allow modification of the electronic and (especially) steric properties. Transmetalation of $\mathrm{Sn}\left[\mathrm{N}\left(\mathrm{SiMe}_{2} \mathrm{CH}_{2}\right)_{2}\right]_{2}$ with calcium in THF yields the corresponding tris(thf) adduct of calcium bis(2,2,5,5-tetramethyl-1-aza-2,5-disilylcyclopentanide). ${ }^{15}$ In contrast, enlargement of the amido ligand and the use of $\mathrm{Sn}\left[\mathrm{N}\left(\mathrm{SiMe}_{3}\right) \mathrm{Si}\left(\mathrm{SiMe}_{3}\right)_{3}\right]_{2}$ in the transmetalation procedure only gives the aminyl radicals and finally the amine $\mathrm{HN}\left(\mathrm{SiMe}_{3}\right) \mathrm{Si}\left(\mathrm{SiMe}_{3}\right)_{3}$, but a calcium bis(amide) cannot be isolated. Suitable procedures for the preparation of $\mathrm{Ca}\left[\mathrm{N}\left(\mathrm{SiHMe}_{2}\right)_{2}\right]_{2}$ are the metathetical approach with $\mathrm{KN}\left(\mathrm{SiHMe}_{2}\right)_{2}$ and $\mathrm{CaI}_{2}$ as well as the transamination of $\mathrm{Ca}(\mathrm{HMDS})_{2}$ with $\mathrm{HN}\left(\mathrm{SiHMe}_{2}\right)_{2} \cdot{ }^{16}$ The metathesis reaction of the potassium amides with calcium iodide offers access to solvated bulky calcium bis(amides) with amido ligands like

Biographical Sketches

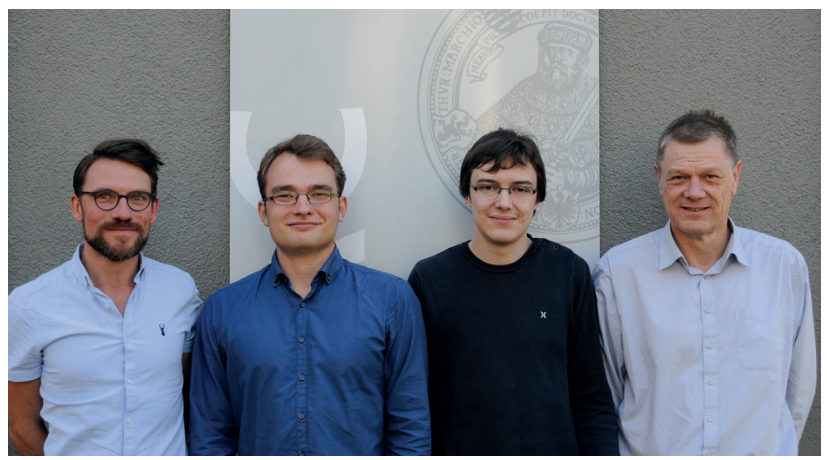

Sven Krieck (left) studied chemistry at Friedrich Schiller University Jena, Germany, and graduated in 2007 with his diploma thesis in the field of electrochemical studies on heterosupramolecular aggregates in the group of Professor Günter Kreisel. He then joined the group of Professor Matthias Westerhausen and completed his Ph.D. in April 2010 working on the stabilization of organocalcium compounds. His thesis was awarded with the university prize as best thesis in 2010 . After a postdoctoral fellowship with Professor Nadia Mösch-Zanetti at Karl Franzens University in Graz, Austria, he returned to the Westerhausen group in 2011. Today he is lecturer at the Institute of Inorganic and Analytical Chemistry at Friedrich Schiller University Jena, Germany.
Philipp Schüler (second from left) studied the synthesis and coordination chemistry of alkaline earth metal bis[bis(trimethylsilyl)amides] at Friedrich Schiller University Jena, Germany, and obtained his M.Sc. degree in 2018. He is currently a Ph.D. student in the Westerhausen group at the same institution.

Jan M. Peschel (second from right) studied chemistry at Friedrich Schiller University Jena, Germany, and obtained his B.Sc. degree in 2017. During his laboratory courses he investigated the synthesis and coordination chemistry of alkaline earth metal bis[bis(trimethylsilyl)amides].

Matthias Westerhausen (right) obtained his diploma degree in chemistry in 1983 from Philipps University in Marburg, Germa- ny, and studied for his Ph.D. thesis at the University of Stuttgart, Germany, under the supervision of Professor Gerd Becker. In $1987 / 88$, he worked as a postdoctoral fellow with Professor Robert T. Paine at the University of New Mexico in Albuquerque, USA, in the field of phosphanylboranes. Back at the University of Stuttgart, he finished his habilitation in the Institute of Inorganic Chemistry in December 1994 and received the venia legendi for Inorganic Chemistry in February 1995. From 1996 to 2004 he was a professor at Ludwig Maximilians University Munich where he was also vice rector from 2001 to 2004. He was awarded the Teaching Excellence Award of the State of Bavaria in 1998. Since 2004, he has been teaching and researching at Friedrich Schiller University Jena, Germany. 
$\mathrm{N}\left(\mathrm{SiMe}_{3}\right)\left(\mathrm{SiMe}_{2} \mathrm{tBu}\right), \quad \mathrm{N}\left(\mathrm{SiMe}_{3}\right)\left(\mathrm{SiPh}_{2} \mathrm{tBu}\right), \quad$ and $\mathrm{N}\left(\mathrm{SiMe}_{3}\right)\left(\mathrm{SiPh}_{3}\right) \cdot{ }^{17}$ The salt metathesis reaction even allows the synthesis of unsolvated calcium bis[bis(triisopropylsilyl)amide] with a nearly linear $\mathrm{N}-\mathrm{Ca}-\mathrm{N}$ fragment of $172.62(11)^{\circ} .{ }^{18}$ This metathetical approach also provides access to substituted $N$-trimethylsilylanilides with bulky aryl groups like 2,4,6-trimethylphenyl (mesityl, Mes) ${ }^{19}$ and 2,6diisopropylphenyl (Dipp). ${ }^{20}$

Furthermore, the co-ligands of $\mathrm{Ca}(\mathrm{HMDS})_{2}$ can be varied to also influence the shielding of the reactive $\mathrm{Ca}-\mathrm{N}$ bonds. Structural studies have been reported for dimeric $\left[\mathrm{Ca}(\mathrm{HMDS})_{2}\right]_{2}{ }^{21}$ as well as for the ether solvates $\left[(\right.$ dme $\left.) \mathrm{Ca}(\mathrm{HMDS})_{2}\right],{ }^{21} \quad\left[(\text { thf })_{2} \mathrm{Ca}(\mathrm{HMDS})_{2}\right],{ }^{22}$ and $\left[(\text { thp })_{2} \mathrm{Ca}(\mathrm{HMDS})_{2}\right] .{ }^{23}$ Electroneutral co-ligands with nitrogen donor atoms like tmeda ${ }^{24}$ and imidazole ${ }^{25}$ form stable complexes too. N-Heterocyclic carbenes are strong $\sigma$-donors and as such they are strong ligands for complexation of $\mathrm{Ca}(\mathrm{HMDS})_{2}$, comparable to hexamethylphosphoric acid triamide. ${ }^{26}$

Since the discovery of these Ca(HMDS) $)_{2}$ complexes in the early 1990s, multiple application fields have been established such as materials science, as ligand transfer and metalation reagents, as precursors in hydrofunctionalization reactions, and as polymerization initiators. This demand justifies an ongoing interest in these calcium complexes leading to a vast development of improved preparative protocols and expansion of the fields of application. Beneficial properties of this alkaline earth metal are based on its position in the periodic table between the alkali metals (highly electropositive metal, ionic $\mathrm{Ca}-\mathrm{N}$ bonds) and the early transition metals (d-orbital participation, highly Lewis acidic ions, catalytic activity). Other useful properties include non-toxicity, global abundance, and the inexpensive nature of this alkaline earth metal.

Due to these reasons, we have developed a straightforward strategy for the synthesis of $\mathrm{Ca}(\mathrm{HMDS})_{2}$ that allows the production of a large amount of this reagent without the necessity to prepare a metalorganic precursor. Furthermore, this method is not limited to the bis(trimethylsilyl)amides, but also allows the synthesis of other as yet unknown calcium bis(amides).

\section{The In Situ Grignard Metalation Method (iGMM)}

Calcium readily forms heavy Grignard reagents via the direct synthesis of activated calcium metal ( $\left.\mathrm{Ca}^{*}\right)$ with iodoand bromoarenes or iodomethyl- and bromomethyltrimethylsilane yielding $\mathrm{ArCaX}$ or $\mathrm{Me}_{3} \mathrm{SiCH}_{2} \mathrm{CaX}(\mathrm{X}=\mathrm{Br}, \mathrm{I})$. However, aliphatic hydrocarbylcalcium halides ( $\mathrm{RCaX})$ are not accessible via this approach (with the exception of cyclopropylcalcium halide). ${ }^{27}$ Instead, Wurtz-type C-C coupling reactions dominate and alkanes $\mathrm{R}-\mathrm{R}$ form nearly quantitatively. The reason for this strikingly different be- havior of aromatic and aliphatic hydrocarbyl iodides and bromides $\mathrm{R}-\mathrm{X}(\mathrm{X}=\mathrm{Br}, \mathrm{I})$ lies in the nature of the hydrocarbyl halide radical anions after the first electron transfer from the metal onto R-X. Without stabilization of the negative charge (via delocalization into the aryl group or via negative hyperconjugation to the trimethylsilyl groups) the $\mathrm{C}-\mathrm{X}$ bond is elongated much more, easing dissociation into the halide anion and the alkyl radical.

Calcium is unable to directly metalate (H)HMDS in common organic solvents (aliphatic and aromatic hydrocarbons, ethers) regardless of a prior activation procedure. Therefore, commercially available calcium granules and this amine were placed together in a Schlenk flask in THF. Next, ethyl bromide, dissolved in THF, was added dropwise at room temperature and the reaction mixture was stirred for an additional three hours to complete the reaction. This reaction is summarized in Scheme 2.

$$
2 \mathrm{Ca}+2 \mathrm{HN}\left(\mathrm{SiMe}_{3}\right)_{2} \underset{\mathrm{THF}, \mathrm{rt}, 5 \mathrm{~h}}{2 \mathrm{RX}}\left(\mathrm{thf}_{4} \mathrm{CaX}_{2}+\left[(\text { thf })_{2} \mathrm{Ca}\left\{\mathrm{N}\left(\mathrm{SiMe}_{3}\right)_{2}\right\}_{2}\right]\right.
$$

Scheme 2 The straightforward synthesis of $\left[(\text { thf })_{2} \mathrm{Ca}(\mathrm{HMDS})_{2}\right]$ in THF using the in situ Grignard metalation method (iGMM)

The calcium turnings slowly dissolve and evolution of ethane was observed. Equimolar amounts of calcium bromide and $\mathrm{Ca}$ (HMDS) $)_{2}$ formed with the Schlenk-type equilibrium being in favor of the homoleptic compounds. This finding is in agreement with earlier studies. ${ }^{24}$ This procedure also worked nicely with magnesium turnings, however, in this case, the equilibrium lies completely on the side of the heteroleptic complex (HMDS)MgBr, an important Hauser base with strong metalating power (Scheme 3). Addition of 1,4-dioxane leads to an equilibrium between the Hauser base on the one side and homometallic $\mathrm{Mg}(\mathrm{HMDS})_{2}$ and magnesium bromide on the other (see the Supporting Information). In the past, these Hauser bases had to be prepared via metalation of bis(trimethylsilyl)amine with previously prepared alkylmagnesium bromide. Alternatively, homoleptic $\mathrm{Mg}(\mathrm{HMDS})_{2}$ can be prepared by an organometallic metalation of (H)HMDS with commercially available dibutylmagnesium, thereby avoiding formation of the Hauser base reagent.

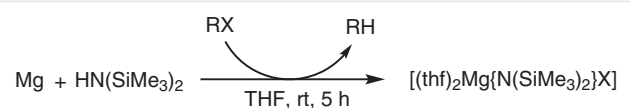

Scheme 3 The straightforward synthesis of the Hauser base $\left[(\text { thf })_{2} \mathrm{Mg}(\mathrm{HMDS}) \mathrm{X}\right]$ in THF using the in situ Grignard metalation method (iGMM)

The results with respect to the reaction conditions are summarized in Table 1 . An equimolar amount of calcium granules and bromoethane leads to a conversion of only $43 \%$ (entry 1 ) because ether cleavage (formation of $\mathrm{R}-\mathrm{H}$ ) 
and Wurtz-type coupling reactions (formation of R-R) compete with the deprotonation of (H)HMDS. If another half equivalent of $\mathrm{EtBr}$ is added after two hours almost complete conversion is obtained (entry 2). Activation of the calcium metal and the use of pyrophoric activated calcium powder accelerates the reaction and higher yields are achieved (entries 3 and 4). The use of iodoethane gave a very similar yield (entry 5). Larger alkyl groups lower the yields significantly, whereas the calciation of (H)HMDS cannot be initiated by a chloroalkane (entry 7). Benzyl bromide, too, is a suitable initiator (entry 12). Contrary to this finding, bromobenzene shows no activation properties in agreement with earlier studies, with aryl halides only reacting with activated calcium.

Table 1 Synthesis of [(thf $\left.)_{2} \mathrm{Ca}(\mathrm{HMDS})_{2}\right]$ Using the In Situ Grignard Metalation Method (iGMM) and Different Alkyl Halides (R-X)

\begin{tabular}{cllll}
\hline Entry & & Ca (equiv) & $\mathrm{R}-\mathrm{X}$ & Conversion (\%) \\
\hline 1 & $\mathrm{Ca}$ & 1 & $\mathrm{EtBr}$ & 43 \\
2 & $\mathrm{Ca}$ & 1.5 & $\mathrm{EtBr}$ & $80^{\mathrm{c}}$ \\
3 & $\mathrm{Ca}+5 \% \mathrm{Ca}^{*}$ & 1 & $\mathrm{EtBr}$ & 60 \\
4 & $\mathrm{Ca}^{*}$ & 1 & $\mathrm{EtBr}$ & 78 \\
5 & $\mathrm{Ca}$ & 1 & $\mathrm{Etl}$ & 42 \\
6 & $\mathrm{Ca}$ & 1 & $\mathrm{PrBr}$ & 10 \\
7 & $\mathrm{Ca}$ & 1 & $\mathrm{BuCl}$ & - \\
8 & $\mathrm{Ca}$ & 1 & $\mathrm{BuBr}$ & 17 \\
9 & $\mathrm{Ca}$ & 1 & $\mathrm{Bul}$ & 17 \\
10 & $\mathrm{Ca}$ & 1 & $1,4-\mathrm{Br}_{2} \mathrm{Bu}$ & 13 \\
11 & $\mathrm{Ca}$ & 1 & $\mathrm{PhBr}$ & - \\
12 & $\mathrm{Ca}$ & 1 & $\mathrm{BnBr}$ & 48
\end{tabular}

a General conditions: $\mathrm{Ca}(2 \mathrm{~g}, 50 \mathrm{mmol})$ in THF $(45 \mathrm{~mL})$ and $(\mathrm{H}) \mathrm{HMDS}(9.8 \mathrm{~mL}$, $45 \mathrm{mmol}$ ) were placed in a Schlenk flask. The hydrocarbyl halide $(\mathrm{R}-\mathrm{X})(50$ $\mathrm{mmol}$ ) in THF (5 mL) was added dropwise over $30 \mathrm{~min}$ and the mixture was stirred for $3 \mathrm{~h}$ at room temperature.

${ }^{\mathrm{b}}$ The conversion was determined by acidimetric titration of an aliquot $(1 \mathrm{~mL})$ after hydrolyzation in $\mathrm{EtOH} / \mathrm{H}_{2} \mathrm{O}(20 \mathrm{~mL}, 1: 1)$ with $\mathrm{H}_{2} \mathrm{SO}_{4}(0.1 \mathrm{M})$ against thymolphthaleine.

c Additional EtBr (1 equiv) was added after $2 \mathrm{~h}$.

The thus prepared solutions of $\left[(\text { thf })_{2} \mathrm{Ca}(\mathrm{HMDS})_{2}\right]$ contain small amounts of calcium bromide according to the solubility of this salt (16 mg of $\mathrm{CaBr}_{2}$ in $1 \mathrm{~mL}$ of THF or 40 $\mathrm{mg}$ of [(thf $\left.)_{4} \mathrm{CaBr}_{2}\right]$ in $1 \mathrm{~mL}$ of THF, respectively). Quantitative removal of calcium bromide is possible via recrystallization of $\mathrm{Ca}(\mathrm{HMDS})_{2}$ from a mixture of THF and alkanes. Formation of $\mathrm{CaBr}_{2}$ proved to be advantageous because this calcium halide precipitates much more easily than $\mathrm{CaI}_{2}$, which also coats the calcium turnings decelerating the conversion. Taking all these facts into account, the preferred strategy uses bromoethane and 1.5 equivalents of calcium. Iodo- and bromomethane are not suitable because the formed methane carries out these volatile halides from the reaction mixture.
These refined reaction conditions were applied to screen the generality of this iGMM (Scheme 4). Commercially available calcium chunks and primary or secondary amines are combined in THF at room temperature. Then bromoethane, dissolved in THF, was added dropwise. A gentle metalation reaction starts yielding the calcium bis(amide) and calcium bromide.

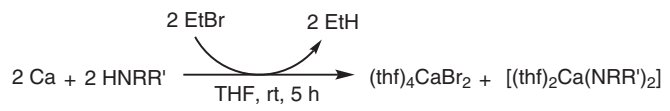

Scheme 4 The straightforward synthesis of $\left[(\text { thf })_{2} \mathrm{Ca}\left(\mathrm{NRR}^{\prime}\right)_{2}\right]$ in THF using the in situ Grignard metalation method (iGMM)

The results are listed in Table 2 together with the standardized reaction conditions. In all cases, 1.5 equivalents of calcium turnings were used and combined with 1 equivalent of the amine in THF. Then bromoethane was added dropwise over a period of 30 minutes at room temperature. The presence of one trialkylsilyl substituent on the nitrogen atom ensures a smooth reaction with high yields, regardless of the bulkiness of the trialkylsilyl group (entries 1 and 46). Also, mixed alkyl-trimethylsilylamine (entry 5) represents a suitable substrate under these reaction conditions. Anilines can also be calciated under these conditions (entry 3 ), however, the yield is lower and longer reaction times are required. Dialkylamines (entry 2) immediately form ammonium bromides during the addition of bromoethane, hampering the calciation reaction. For the same reason, primary and secondary phosphanes are not calciated under these reaction conditions, but phosphonium bromides are formed during the addition of bromoethane.

In summary, aryl- (anilides) and trialkylsilyl-substituted amides of calcium are accessible via this novel iGMM. Commercially available calcium granules are a suitable substrate for the calciation of these primary and secondary

Table 2 Synthesis of $\left[(\text { thf })_{n} \mathrm{Ca}\left(\mathrm{NR}_{2}\right)_{2}\right]$ using the In Situ Grignard Metalation Method (iGMM)

\begin{tabular}{lll}
\hline Entry & $\mathrm{R}_{2} \mathrm{NH}$ & Conversion (\%) \\
\hline 1 & $(\mathrm{H}) \mathrm{HMDS}$ & 80 \\
2 & $\mathrm{Cy}_{2} \mathrm{NH}$ & - \\
3 & $\mathrm{Ph}_{2} \mathrm{NH}$ & 43 \\
4 & $i \mathrm{Pr}_{3} \mathrm{SiNH}_{2}$ & 86 \\
5 & $t \mathrm{Bu}_{2}(\mathrm{NH}) \mathrm{TMS}$ & 92 \\
6 & $\mathrm{Ph}_{3} \mathrm{SiNH}_{2}$ & 78 \\
\hline
\end{tabular}

a General conditions: $\mathrm{Ca}$ ( $2.75 \mathrm{~g}, 68 \mathrm{mmol}, 1.5$ equiv) in THF ( $45 \mathrm{~mL})$ and $\mathrm{R}_{2} \mathrm{NH}(45 \mathrm{mmol})$ were placed in a Schlenk flask. EtBr $(3.4 \mathrm{~mL}, 45 \mathrm{mmol})$ in THF $(5 \mathrm{~mL})$ was added dropwise over $30 \mathrm{~min}$ and the mixture was stirred for $3 \mathrm{~h}$ at room temperature.

b The conversion was determined by acidimetric titration of an aliquot (1 $\mathrm{mL}$ ) after hydrolyzation in $\mathrm{EtOH} / \mathrm{H}_{2} \mathrm{O}(20 \mathrm{~mL}, 1: 1)$ with $\mathrm{H}_{2} \mathrm{SO}_{4}(0.1 \mathrm{M})$ against thymolphthaleine. 
amines. In contrast to the calcium-based procedure, Hauser bases form if magnesium turnings are used in this reaction. Due to competing Wurtz-type coupling reactions a slight excess of calcium is beneficial. This synthesis of $\mathrm{Ca}(\mathrm{HMDS})_{2}$ can easily be upscaled to multigram scale without preceding elaborate and time-consuming preparations (such as purification and activation of calcium, preparation of calciation reagents or dealing with ammonia-saturated ethereal solvents).

The results are depicted in Scheme 5. Direct metalation of (H)HMDS and other amines with calcium in THF is impossible. Addition of bromoethane to this mixture at room temperature initiates a gentle and smooth deprotonation and formation of $\mathrm{Ca}(\mathrm{HMDS})_{2}$. Ethane escapes from this reaction and calcium bromide precipitates without disturbance of the ongoing calciation process. Heteroleptic (HMDS)CaBr cannot be observed whereas the use of magnesium turnings favors the formation of the Hauser base (HMDS)MgBr. Addition of 1,4-dioxane leads to an equilibrium between the heteroleptic Hauser base on the one side and the homoleptic complexes $\mathrm{Mg}(\mathrm{HMDS})_{2}$ and $\mathrm{MgBr}_{2}$ on the other.

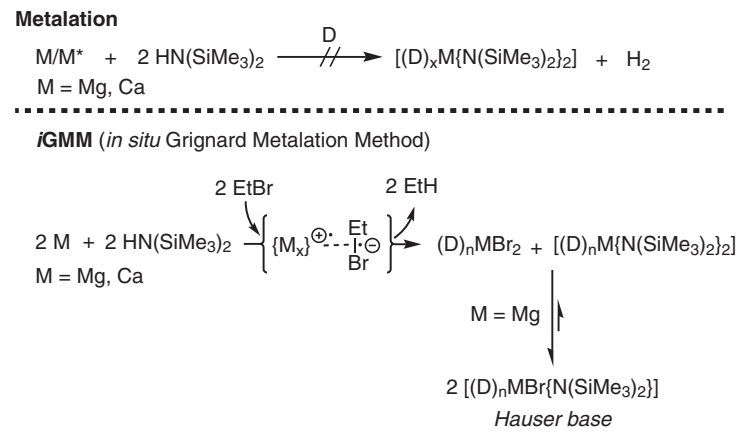

Scheme 5 Synthesis of $\mathrm{Mg}(\mathrm{HMDS})_{2}$ and $\mathrm{Ca}(\mathrm{HMDS})_{2}$ using the in situ Grignard metalation method (iGMM)

The thus prepared $\mathrm{Ca}(\mathrm{HMDS})_{2}$ is free of other metals, but the solution contains calcium bromide which does not interfere with the reactivity of the amide because Hauserbase-like products have not been observed in these ethereal solutions. Nevertheless, removal of calcium bromide can easily be achieved. For this purpose, all volatile materials are removed in vacuo and the remaining residue is extracted with pentane. Calcium bromide is insoluble in alkanes whereas the calcium amides precipitate as colorless crystals upon cooling of this alkane solution.

In summary, the $i G M M$ is an extremely valuable and straightforward procedure to prepare quantitatively, on a multigram scale, new calcium bis(amides) with aryl or tris(hydrocarbyl)silyl substituents at the nitrogen atom and, also for the preparation of heteroleptic amidomagnesium bromide (Hauser base) solutions. The magnesiumbased Hauser bases and their calcium-based congeners can be used as strong metalation reagents and furthermore, amidomagnesium halides containing stoichiometric amounts of $\mathrm{LiCl}$ are known as Turbo-Hauser bases. ${ }^{28}$

\section{Properties of $\left[(\text { thf })_{2} \mathrm{M}(\mathrm{HMDS})_{2}\right]$}

The bis(trimethylsilyl)amides of the alkaline earth metals magnesium, calcium, strontium, and barium form bis(thf) adducts with distorted tetrahedral coordination spheres of the metal centers., ${ }^{1,22,29}$ These bis(thf) adducts $\left[(\text { thf })_{2} \mathrm{M}(\mathrm{HMDS})_{2}\right]$ show characteristic NMR parameters that are summarized in Table $3 .^{2,10 \mathrm{~b}}$ With increasing electronegativity of the central metal atom, the resonances of the ${ }^{29} \mathrm{Si}$ nucleus show a high-field shift due to back donation of negative charge from the nitrogen atom into the $\sigma^{*}(\mathrm{Si}-\mathrm{C})$ bonds, a property known as negative hyperconjugation. If only one trimethylsilyl group is bound at the nitrogen atom, then this effect is enhanced leading to increased hyperconjugative effects and an even stronger high-field shift of the ${ }^{29} \mathrm{Si}$ resonance as observed for $\left[(\text { thf })_{2} \mathrm{Ca}\left\{\mathrm{N}(t \mathrm{Bu})\left(\mathrm{SiMe}_{3}\right)\right\}_{2}\right]$ with a value of $\delta=-20.7$. The $\delta\left({ }^{15} \mathrm{~N}\left\{{ }^{1} \mathrm{H}\right\}\right)$ values of the $\left[{ }^{15} \mathrm{~N}\right]-$ labeled complexes also strongly depend on the size and hardness of the alkaline earth metal.

Table 3 NMR data ${ }^{a}$ of the HMDS Ligand of the Alkaline Earth Metal $\left[(\text { thf })_{2} \mathrm{M}(\mathrm{HMDS})_{2}\right]$ Complexes $^{2,10 \mathrm{~b}}$

\begin{tabular}{lrrcc}
\hline$M$ & $M g$ & $\mathrm{Ca}$ & $\mathrm{Sr}$ & $\mathrm{Ba}$ \\
\hline$\delta\left({ }^{1} \mathrm{H}\right)$ & 0.35 & 0.33 & 0.33 & 0.32 \\
$\delta\left({ }^{13} \mathrm{C}\left[{ }^{1} \mathrm{H}\right\}\right)$ & 6.60 & 5.69 & 5.93 & 5.73 \\
${ }^{1}\left({ }^{29} \mathrm{Si},{ }^{13} \mathrm{C}\right)$ & 52.8 & 51.5 & 51.8 & 51.9 \\
${ }^{2}\left({ }^{15} \mathrm{~N},{ }^{13} \mathrm{C}\right)^{\mathrm{b}}$ & 2.3 & 2.5 & 2.4 & 2.3 \\
$\delta\left({ }^{15} \mathrm{~N}\left[{ }^{1} \mathrm{H}\right\}\right)^{\mathrm{b}}$ & -345.5 & -304.5 & -301.9 & -275.9 \\
$\delta\left({ }^{29} \mathrm{Si}\left[{ }^{1} \mathrm{H}\right\}\right)$ & -8.6 & -15.0 & -16.7 & -18.4 \\
${ }^{1}\left({ }^{29} \mathrm{Si},{ }^{15} \mathrm{~N}\right)^{\mathrm{b}}$ & 8.1 & 9.0 & 9.1 & 9.9
\end{tabular}

a Chemical shifts $(\delta)$ are quoted in ppm and coupling constants $(J)$ in $\mathrm{Hz}$.

b These values were determined using $\left[{ }^{15} \mathrm{~N}\right]$-labeled compounds.

The molecular structures of the $\left[(\text { thf })_{2} \mathrm{M}(\mathrm{HMDS})_{2}\right]$ complexes are very much alike with characteristic trends dependent on the size and electronegativity of the alkaline earth metal. Selected values are listed in Table 4. As expected, the $\mathrm{M}-\mathrm{N}$ and $\mathrm{M}-\mathrm{O}$ bond lengths increase with the radius of the metal. Decreasing intramolecular repulsion with increasing size of the metal center is evident from the decreasing $\mathrm{N}-\mathrm{M}-\mathrm{N}$ bond angles from $\mathrm{Mg}$ to $\mathrm{Ba}$. The $\mathrm{N}-\mathrm{Si}$ bond lengths are rather small due to negative hyperconjugation. This interaction leads to large $\mathrm{Si}-\mathrm{N}-\mathrm{Si}$ bond angles.

Due to steric shielding of the reactive $\mathrm{M}-\mathrm{N}$ bonds by the bulky HMDS ligands, these complexes show only a moderate sensitivity toward air and hence, isolated crystalline 
material as well as stock solutions are very durable and can be used for stoichiometric and catalytic chemical conversions.

Table 4 Selected Structural Parameters (Average Values, Bond Lengths [pm] and Angles [ $\left.{ }^{\circ}\right]$ ) of the Alkaline Earth Metal $\left[(\text { thf })_{2} \mathrm{M}(\mathrm{HMDS})_{2}\right]$ Complexes

\begin{tabular}{lcccc}
\hline $\mathrm{M}$ & $\mathrm{Mg}$ & $\mathrm{Ca}$ & $\mathrm{Sr}$ & $\mathrm{Ba}$ \\
\hline $\mathrm{M}-\mathrm{N}$ & 202.1 & 230.2 & 245.8 & 259.2 \\
$\mathrm{M}-\mathrm{O}$ & 209.4 & 237.7 & 253.4 & 273.1 \\
$\mathrm{~N}-\mathrm{M}-\mathrm{N}$ & 127.9 & 121.3 & 120.6 & 116.8 \\
$\mathrm{O}-\mathrm{M}-\mathrm{O}$ & 89.8 & 81.4 & 84.7 & 91.4 \\
$\mathrm{~N}-\mathrm{Si}$ & 170.6 & 168.6 & 167.4 & 168.0 \\
Si-N-Si & 121.0 & 126.3 & 132.3 & 131.7 \\
Ref. & 1 & 22 & 22 & 29 \\
\hline
\end{tabular}

\section{Applications and Perspective}

In the initial 15 years after the first preparation of these $\left[(\text { thf })_{2} \mathrm{M}(\mathrm{HMDS})_{2}\right]$ complexes of magnesium ${ }^{1}$ and calcium, ${ }^{2}$ the physical and chemical properties have been elucidated in detail. For approximately 20 years, widespread stoichiometric and catalytic applications have been identified and explored, especially for these environmentally benign magnesium and calcium complexes. A few representative examples are discussed below.

The complexes $\left[(\text { thf })_{2} \mathrm{M}(\mathrm{HMDS})_{2}\right](\mathrm{M}=\mathrm{Mg}, \mathrm{Ca})$ are valuable synthons in metalation reactions of acidic compounds; early reactivity studies include examples of the synthesis of phosphanides, ${ }^{30}$ thiolates, ${ }^{31}$ selenolates, ${ }^{32}$ tellurolates, ${ }^{32}$ metallocenes, ${ }^{33}$ and alkynyl complexes. ${ }^{34}$ Lewis acid-base reactions with trialkylalanes ${ }^{35}$ and -gallanes ${ }^{36}$ allowed the synthesis of $\mathrm{Ca}-\mathrm{C}$ bonds to bridging alkyl groups. Very recently, dimethylcalcium was prepared via a ligand exchange between $\mathrm{Ca}(\mathrm{HMDS})_{2}$ and methyllithium. ${ }^{37}$ Addition of [(thf $\left.)_{2} \mathrm{Ca}(\mathrm{HMDS})_{2}\right]$ to nitriles allows the synthesis of amidinates with high yields. ${ }^{38}$ Recently, these compounds also allowed the synthesis of calcium hydride cages. ${ }^{39}$

Besides these stoichiometric conversions many catalytic applications have recently been elucidated. The non-toxic nature of $\mathrm{Ca}(\mathrm{HMDS})_{2}$ accelerates its use for the synthesis of biopolymers such as polylactides. ${ }^{40}$ For diverse catalytic processes, $\mathrm{Ca}(\mathrm{HMDS})_{2}$ is a valuable and easy-to-handle precatalyst. Representative examples include the calcium-mediated hydroamination of unsaturated compounds (like alkenes, alkynes, heterocumulenes) ${ }^{41}$ as well as the hydroacetylenation of carbodiimides. ${ }^{42}$ Inorganic-organic hybrid materials have also been prepared and functionalized using this compound as a catalyst. ${ }^{43}$

These selected examples demonstrate the necessity of a simple and straightforward synthesis of $\left[(\text { thf })_{2} \mathrm{M}(\mathrm{HMDS})_{2}\right]$ $(\mathrm{M}=\mathrm{Mg}, \mathrm{Ca})$ with high yields that can be safely performed without the requirement of sophisticated preparative skills. This novel iGMM fulfills all preconditions for an easy access to widely use these environmentally benign reagents.

All manipulations were carried out under an inert nitrogen atmosphere using standard Schlenk techniques unless otherwise noted. All substrates were purchased from Alfa Aesar, abcr, Sigma Aldrich, or TCI and were used without further purification. The solvents were dried over $\mathrm{KOH}$ and subsequently distilled over sodium/benzophenone under a nitrogen atmosphere prior to use. Deuterated solvents were dried over sodium, distilled, degassed, and stored under nitrogen over sodium. $\mathrm{HN}(\mathrm{tBu})\left(\mathrm{SiMe}_{3}\right)^{40}$ and $i \mathrm{Pr}_{3} \mathrm{SiNH}_{2}{ }^{41}$ were prepared according to literature protocols. The yields given are crystalline yields and not optimized. IR spectra were recorded on a Bruker Alpha spectrometer. ${ }^{1} \mathrm{H}$, ${ }^{29} \mathrm{Si}$ and ${ }^{13} \mathrm{C}\left\{{ }^{1} \mathrm{H}\right\}$ NMR spectra were recorded on a Bruker Avance III 400 spectrometer. Chemical shifts are reported in parts per million relative to $\mathrm{SiMe}_{4}$ as an external standard referenced to the residual proton signal of the solvent. The purity of the compounds was verified by NMR spectroscopy.

\section{[(thf $)_{2} \operatorname{MgBr}($ HMDS $\left.)\right]$}

Magnesium (0.97 g, $40.4 \mathrm{mmol}, 1.1$ equiv) was suspended in THF (45 $\mathrm{mL}$ ) and (H)HMDS (5.9 g, $36.4 \mathrm{mmol}$ ) was added in one portion. EtBr ( $2.7 \mathrm{~mL}, 36.4 \mathrm{mmol}, 1$ equiv) was added dropwise over 30 min yielding a clear slightly yellow solution which can be used as a stock solution for this Hauser base ( $0.87 \mathrm{M}$, quant.). Excess magnesium metal was removed by filtration.

${ }^{1} \mathrm{H}$ NMR (400 MHz, $\left.\mathrm{C}_{6} \mathrm{D}_{6}, 296 \mathrm{~K}\right): \delta=3.73(\mathrm{~m}, 8 \mathrm{H}, \mathrm{thf}), 1.44(\mathrm{~m}, 8 \mathrm{H}$, thf), $0.23\left(\mathrm{~s}, 18 \mathrm{H}, \mathrm{SiMe}_{3}\right)$.

${ }^{13} \mathrm{C}\left\{{ }^{1} \mathrm{H}\right\}$ NMR (101 MHz, $\left.\mathrm{C}_{6} \mathrm{D}_{6}, 296 \mathrm{~K}\right): \delta=69.7$ (thf), 24.8 (thf), 5.9 $\left(\mathrm{SiMe}_{3}\right)$.

${ }^{29} \mathrm{Si}-{ }^{1} \mathrm{H}$ NMR (79.5 MHz, $\left.\mathrm{C}_{6} \mathrm{D}_{6}, 296 \mathrm{~K}\right): \delta=-8.1$.

\section{[(thf $\left.)_{2} \mathbf{C a}(\mathrm{HMDS})_{2}\right]$}

Calcium (2.0 g, 50 mmol, 1.1 equiv), (H)HMDS (9.6 mL, 45.4 mmol, 1 equiv) and THF ( $45 \mathrm{~mL}$ ) were placed in a Schlenk flask. EtBr $(3.4 \mathrm{~mL}$, $45.4 \mathrm{mmol}, 1$ equiv) in THF ( $5 \mathrm{~mL})$ was added dropwise while a moderate gas evolution was observed. The slurry was stirred for $2 \mathrm{~h}$, a second amount of $\operatorname{EtBr}(2 \mathrm{~mL}, 26.8 \mathrm{mmol}, 0.6$ equiv) was added in one portion and the mixture was stirred for $2 \mathrm{~h}$ at room temperature. The solution was decanted and could be used after acidimetric titration $(0.62 \mathrm{M})$ as a stock solution in organic synthesis $\left(\mathrm{Br}^{-}\right.$concentration: $0.17 \mathrm{~mol} / \mathrm{L})$.

The crystalline compound $\left[(\text { thf })_{2} \mathrm{Ca}(\mathrm{HMDS})_{2}\right]$ was isolated as follows: The solvents were removed under reduced pressure and the residue redissolved in a mixture of $n$-pentane/THF $(1 \times 40 \mathrm{~mL}: 1 \mathrm{~mL})$ and filtered through a frit covered with diatomaceous earth (or separated via decantation/centrifugation). The filtrate was stored at $-40{ }^{\circ} \mathrm{C}$ yielding solid $\left[(\text { thf })_{2} \mathrm{Ca}(\mathrm{HMDS})_{2}\right]$ as colorless and halide-free crystals which were collected and dried in vacuo $(6.2 \mathrm{~g}, 12 \mathrm{mmol}, 49 \%$ ).

The analytical data are in accordance with the literature parameters. ${ }^{1,2}$

\section{$\left[(\text { thf })_{2} \mathrm{Ca}\left\{\mathrm{N}(\mathrm{tBu})\left(\mathrm{SiMe}_{3}\right)\right\}_{2}\right]$}

Calcium (1.0 g, $27 \mathrm{mmol}, 1.5$ equiv), $\mathrm{HN}(\mathrm{tBu})\left(\mathrm{SiMe}_{3}\right)(2.6 \mathrm{~g}, 18 \mathrm{mmol}$, 1 equiv) and THF $(30 \mathrm{~mL})$ were placed in a Schlenk flask. EtBr $(1.4 \mathrm{~mL}$, $18 \mathrm{mmol}, 1$ equiv) was added dropwise. After complete addition, a colorless precipitate of calcium bromide formed. A second equivalent 
of $\operatorname{EtBr}(1.4 \mathrm{~mL}, 18 \mathrm{mmol}, 1$ equiv) was added in one portion and the reaction mixture was stirred overnight at room temperature. After decanting of the supernatant, one aliquot of the solution was titrated by acidimetric titration $(0.51 \mathrm{M})$. The solvent was removed under reduced pressure, the residue was redissolved in with $n$-hexane $(40 \mathrm{~mL})$ and filtered through a frit covered with diatomaceous earth. The clear filtrate was stored at $-20^{\circ} \mathrm{C}$ and the obtained precipitate was collected and dried in vacuo yielding the amide as a colorless powder $(2.6 \mathrm{~g}$, $5.5 \mathrm{mmol}, 31 \%)$.

IR (ATR): 2938, 2887, 1460, 1347, 1235, 1194, 1056, 1029, 991, 917, $853,816,752,687,651,611,504,476,432 \mathrm{~cm}^{-1}$.

${ }^{1} \mathrm{H}$ NMR (400 MHz, $\left.\mathrm{C}_{6} \mathrm{D}_{6}, 296 \mathrm{~K}\right): \delta=3.62(\mathrm{t}, J=6.27 \mathrm{~Hz}, 8 \mathrm{H}$, thf), 1.53 (s, $18 \mathrm{H}, t \mathrm{Bu}), 1.28$ (m, $8 \mathrm{H}$, thf), $0.41\left(\mathrm{~s}, 18 \mathrm{H}, \mathrm{SiMe}_{3}\right)$.

${ }^{13} \mathrm{C}$ NMR $\left(101 \mathrm{MHz}, \mathrm{C}_{6} \mathrm{D}_{6}, 296 \mathrm{~K}\right): \delta=69.3$ (thf), $52.7(t \mathrm{Bu}), 37.3(t \mathrm{Bu})$, 24.8 (thf), $5.8\left(\mathrm{SiMe}_{3}\right)$.

${ }^{29} \mathrm{Si}-{ }^{1} \mathrm{H}$ DEPT NMR (78.5 MHz, $\left.\mathrm{C}_{6} \mathrm{D}_{6}, 296 \mathrm{~K}\right): \delta=-20.7$.

\section{Acknowledgment}

We acknowledge the valuable support from the NMR service platform (www.nmr.uni-jena.de) of the Faculty of Chemistry and Earth Sciences of Friedrich Schiller University Jena, Germany.

\section{Supporting Information}

Supporting information for this article is available online at https://doi.org/10.1055/s-0037-1610407.

\section{References}

(1) Bradley, D. C.; Hursthouse, M. B.; Ibrahim, A. A.; Malik, K. M. A.; Motevalli, M.; Möseler, R.; Powell, H.; Runnacles, J. D.; Sullivan, A. C. Polyhedron 1990, 9, 2959.

(2) Westerhausen, M. Inorg. Chem. 1991, 30, 96.

(3) Hitchcock, P. B.; Lappert, M. F.; Lawless, G. A.; Royo, B. J. Chem. Soc., Chem. Commun. 1990, 1141.

(4) Frankland, A. D.; Hitchcock, P. B.; Lappert, M. F.; Lawless, G. A. J. Chem. Soc., Chem. Commun. 1994, 2435.

(5) Frankland, A. D.; Lappert, M. F. J. Chem. Soc., Dalton Trans. 1996, 4151.

(6) Tanner, P. S.; Burkey, D. J.; Hanusa, T. P. Polyhedron 1995, 14, 331.

(7) He, X.; Noll, B. C.; Beatty, A.; Mulvey, R. E.; Henderson, K. W. J. Am. Chem. Soc. 2004, 126, 7444.

(8) Brady, E. D.; Hanusa, T. P.; Pink, M.; Young, V. G. Inorg. Chem. 2000, 39, 6028 .

(9) Drake, S. R.; Otway, D. J.J. Chem. Soc., Chem. Commun. 1991, 517.

(10) (a) Westerhausen, M. Trends Organomet. Chem. 1997, 2, 89. (b) Westerhausen, M. Coord. Chem. Rev. 1998, 176, 157.

(11) Gillett-Kunnath, M. M.; MacLellan, J. G.; Forsyth, C. M.; Andrews, P. C.; Deacon, G. B.; Ruhlandt-Senge, K. Chem. Commun. 2008, 4490.

(12) Johns, A. M.; Chmely, S. C.; Hanusa, T. P. Inorg. Chem. 2009, 48, 1380.

(13) (a) Westerhausen, M. Angew. Chem. Int. Ed. 2001, 40, 2975. (b) Westerhausen, M.; Gärtner, M.; Fischer, R.; Langer, J.; Yu, L.; Reiher, M. Chem. Eur. J. 2007, 13, 6292. (c) Westerhausen, M.; Gärtner, M.; Fischer, M.; Langer, J. Angew. Chem. Int. Ed. 2007, 46, 1950. (d) Westerhausen, M. Z. Anorg. Allg. Chem. 2009, 635,
13. (e) Westerhausen, M.; Langer, J.; Krieck, S.; Glock, C. Rev. Inorg. Chem. 2011, 31, 143. (f) Westerhausen, M.; Langer, J.; Krieck, S.; Fischer, R.; Görls, H.; Köhler, M. Top. Organomet. Chem. 2013, 45, 29. (g) Westerhausen, M.; Koch, A.; Görls, H.; Krieck, S. Chem. Eur. J. 2017, 23, 1456.

(14) (a) Gärtner, M.; Fischer, R.; Langer, J.; Görls, H.; Walther, D.; Westerhausen, M. Inorg. Chem. 2007, 46, 5118. (b) Gärtner, M.; Görls, H.; Westerhausen, M. Inorg. Chem. 2007, 46, 7678. (c) Gärtner, M.; Görls, H.; Westerhausen, M. Dalton Trans. 2008, 1574.

(15) Westerhausen, M.; Greul, J.; Hausen, H. D.; Schwarz, W. Z. Anorg. Allg. Chem. 1996, 622, 1295.

(16) Sarazin, Y.; Rosca, D.; Poirier, V.; Roisnel, T.; Silvestru, A.; Maron, L.; Carpentier, J.-F. Organometallics 2010, 29, 6569.

(17) Tang, Y.; Zakharov, L. N.; Kassel, W. S.; Rheingold, A. L.; Kemp, R. A. Inorg. Chim. Acta 2005, 358, 2014.

(18) Leng, J.-D.; Goodwin, C. A. P.; Victoria-Yrezabal, I. J.; Mills, D. P. Dalton Trans. 2018, 47, 12526.

(19) Gillett-Kunnath, M.; Teng, W.; Vargas, W.; Ruhlandt-Senge, K. Inorg. Chem. 2005, 44, 4862.

(20) Vargas, W.; Englich, U.; Ruhlandt-Senge, K. Inorg. Chem. 2002, $41,5602$.

(21) Westerhausen, M.; Schwarz, W. Z. Anorg. Allg. Chem. 1991, 604, 127.

(22) Westerhausen, M.; Hartmann, M.; Makropoulos, N.; Wieneke, B.; Wieneke, M.; Schwarz, W.; Stalke, D. Z. Naturforsch. 1998, $53 b, 117$.

(23) Younis, F. M.; Görls, H.; Krieck, S.; Westerhausen, M. Z. Anorg. Allg. Chem. 2013, 639, 19.

(24) Glock, C.; Görls, H.; Westerhausen, M. Inorg. Chim. Acta 2011, $374,429$.

(25) Arrowsmith, M.; Heath, A.; Hill, M. S.; Hitchcock, P. B.; KociokKöhn, G. Organometallics 2009, 28, 4550.

(26) Barrett, A. G. M.; Crimmin, M. R.; Hill, M. S.; Kociok-Köhn, G.; MacDougall, D. J.; Mahon, M. F.; Procopiou, P. A. Organometallics 2008, 27, 3939.

(27) Koch, A.; Dufrois, Q.; Wirgenings, M.; Görls, H.; Krieck, S.; Etienne, M.; Pohnert, G.; Westerhausen, M. Chem. Eur. J. 2018, 24,16840 .

(28) Recent studies on Turbo-Hauser bases: (a) García-Alvarez, P.; Graham, D. V.; Hevia, E.; Kennedy, A. R.; Klett, J.; Mulvey, R. E.; O'Hara, C. T.; Weatherstone, S. Angew. Chem. Int. Ed. 2008, 47, 8079. (b) Neufeld, R.; Stalke, D. Chem. Eur. J. 2016, 22, 12624. (c) Neufeld, R.; Teuteberg, T. L.; Herbst-Irmer, R.; Mata, R. A.; Stalke, D. J. Am. Chem. Soc. 2016, 138, 4796. (d) Goodwin, C. A. P.; Smith, A.; Ortu, F.; Vitorica-Yrezabal, I. J.; Mills, D. P. Dalton Trans. 2016, 45, 6004.

(29) Vaartstra, B. A.; Huffman, J. C.; Streib, W. E.; Caulton, K. G. Inorg. Chem. 1991, 30, 121.

(30) (a) Westerhausen, M.; Schwarz, W. J. Organomet. Chem. 1993, 463, 51. (b) Westerhausen, M.; Löw, R.; Schwarz, W. J. Organomet. Chem. 1996, 513, 213. (c) Westerhausen, M.; Digeser, M. H.; Krofta, M.; Wiberg, N.; Nöth, H.; Knizek, J.; Ponikwar, W.; Seifert, T. Eur. J. Inorg. Chem. 1999, 743.

(31) Chadwick, S.; Englich, U.; Noll, B.; Ruhlandt-Senge, K. Inorg. Chem. 1998, 37, 4718.

(32) (a) Becker, G.; Klinkhammer, K. W.; Schwarz, W.; Westerhausen, M.; Hildenbrand, T. Z. Naturforsch. 1992, 47b, 1225. (b) Gindelberger, D. E.; Arnold, J. Inorg. Chem. 1994, 33, 6293.

(33) (a) Westerhausen, M.; Hartmann, M.; Schwarz, W.J. Organomet. Chem. 1995, 501, 359. (b) Hays, M.; Hanusa, T. P.; Nile, T. A. J. Organomet. Chem. 1996, 514, 73. (c) Westerhausen, M.; 
Hartmann, M.; Heckmann, G.; Schwarz, W.J. Organomet. Chem. 1997, 541, 261. (d) Li, H.; Zhang, W.-X.; Xi, Z. Chem. Eur. J. 2013, 19,12859 .

(34) Green, D. C.; Englich, U.; Ruhlandt-Senge, K. Angew. Chem. Int. Ed. 1999, 38, 354.

(35) (a) Westerhausen, M.; Birg, C.; Nöth, H.; Knizek, J.; Seifert, T. Eur. J. Inorg. Chem. 1999, 2209. (b) Michel, O.; Meermann, C.; Tornroos, K. W.; Anwander, R. Organometallics 2009, 28, 4783.

(36) Westerhausen, M.; Weinrich, S.; Oßberger, M.; Mitzel, N. W. Z. Anorg. Allg. Chem. 2003, 629, 575.

(37) Wolf, B. M.; Stuhl, C.; Maichle-Mössmer, C.; Anwander, R. J. Am. Chem. Soc. 2018, 140, 2373.

(38) Westerhausen, M.; Schwarz, W. Z. Naturforsch. 1992, 47, 453.

(39) Maitland, B.; Wiesinger, M.; Langer, J.; Ballmann, G.; Pahl, J.; Eisen, H.; Färber, C.; Harder, S. Angew. Chem. Int. Ed. 2017, 56, 11880.

(40) (a) Zhong, Z.; Ankone, M. J. K.; Dijkstra, P. J.; Birg, C.; Westerhausen, M.; Feijen, J. Polym. Bull. 2001, 46, 51. (b) Zhong, Z.; Dijkstra, P. J.; Birg, C.; Westerhausen, M.; Feijen, J. Macromol- ecules 2001, 34, 3863. (c) Zhong, Z.; Schneiderbauer, S.; Dijkstra, P. J.; Westerhausen, M.; Jeijen, J. J. Polym. Environ. 2002, 9, 31. (d) Yildirim, I.; Yildirim, T.; Kalden, D.; Festag, G.; Fritz, N.; Weber, C.; Schubert, S.; Westerhausen, M.; Schubert, U. S. Polym. Chem. 2017, 8, 4378. (e) Bhattacharjee, J.; Harinath, A.; Nayek, H. P.; Sarkar, A.; Panda, T. K. Chem. Eur.J. 2017, 23, 9319.

(41) (a) Barrett, A. G. M.; Boorman, T. C.; Crimmin, M. R.; Hill, M. S.; Kociok-Köhn, G.; Procopiou, P. A. Chem. Commun. 2008, 5206. (b) Lachs, J. R.; Barrett, A. G. M.; Crimmin, M. R.; Kociok-Köhn, G.; Hill, M. S.; Mahon, M. F.; Procopiou, P. A. Eur. J. Inorg. Chem. 2008, 4173. (c) Brinkmann, C.; Barrett, A. G. M.; Hill, M. S.; Procopiou, P. A. J. Am. Chem. Soc. 2012, 134, 2193.

(42) Arrowsmith, M.; Crimmin, M. R.; Hill, M. S.; Lomas, S. L.; Heng, M. S.; Hitchcock, P. B.; Kociok-Köhn, G. Dalton Trans. 2014, 43, 14249.

(43) Achtel, C.; Härling, S. M.; Hering, W.; Westerhausen, M.; Heinze, T. Macromol. Rapid Commun. 2018, 39, 1800199. 